\title{
A chemical screen identifies two novel small compounds that alter Arabidopsis thaliana pollen tube growth
}

\author{
Ferdousse Laggoun ${ }^{1}$, Flavien Dardelle ${ }^{1,4}$, Jérémy Dehors ${ }^{1}$, Denis Falconet ${ }^{2}$, Azeddine Driouich', \\ Christophe Rochais ${ }^{3}$, Patrick Dallemagne ${ }^{3}$, Arnaud Lehner ${ }^{1 *+}$ (D) and Jean-Claude Mollet ${ }^{1 *+}$
}

\begin{abstract}
Background: During sexual reproduction, pollen grains land on the stigma, rehydrate and produce pollen tubes that grow through the female transmitting-tract tissue allowing the delivery of the two sperm cells to the ovule and the production of healthy seeds. Because pollen tubes are single cells that expand by tip-polarized growth, they represent a good model to study the growth dynamics, cell wall deposition and intracellular machineries. Aiming to understand this complex machinery, we used a low throughput chemical screen approach in order to isolate new tip-growth disruptors. The effect of a chemical inhibitor of monogalactosyldiacylglycerol synthases, galvestine-1, was also investigated. The present work further characterizes their effects on the tip-growth and intracellular dynamics of pollen tubes.
\end{abstract}

Results: Two small compounds among 258 were isolated based on their abilities to perturb pollen tube growth. They were found to disrupt in vitro pollen tube growth of tobacco, tomato and Arabidopsis thaliana. We show that these 3 compounds induced abnormal phenotypes (bulging and/or enlarged pollen tubes) and reduced pollen tube length in a dose dependent manner. Pollen germination was significantly reduced after treatment with the two compounds isolated from the screen. They also affected cell wall material deposition in pollen tubes. The compounds decreased anion superoxide accumulation, disorganized actin filaments and RIC4 dynamics suggesting that they may affect vesicular trafficking at the pollen tube tip.

Conclusion: These molecules may alter directly or indirectly ROP1 activity, a key regulator of pollen tube growth and vesicular trafficking and therefore represent good tools to further study cellular dynamics during polarized-cell growth.

Keywords: Pollen tubes, Chemical screen, Callose, Cell wall deposition, Pectins, ROS, Tip-polarized growth, RIC4, Actin dynamics

\section{Background}

During sexual reproduction, pollen grains land on the stigma, rehydrate and produce pollen tubes that grow through the female transmitting-tract tissue allowing a proper delivery of the two sperm cells to the ovule [1]. During this journey, the pollen tube perceives different signals promoting its growth, adhesion and guidance [2-5].

\footnotetext{
* Correspondence: arnaud.lehner@univ-rouen.fr; jean-claude.mollet@univrouen.fr

${ }^{+}$Arnaud Lehner and Jean-Claude Mollet contributed equally to this work. ${ }^{1}$ Normandie Université, UNIROUEN, Laboratoire Glycobiologie et Matrice Extracellulaire Végétale EA4358, Fédération de Recherche "NORVEGE"- FED 4277, 76000 Rouen, France

Full list of author information is available at the end of the article
}

Pollen tube is one of the fastest tip-growing cells. They can reach growth rate from 58 to $400 \mathrm{~nm} . \mathrm{sec}^{-1}$, depending on the species [6]. This implies an extremely efficient system for delivering and modifying membrane and cell wall material at the tip, which is highly coordinated for pollen tube oscillatory growth $[7,8]$. Oscillatory growth is followed by an intracellular tip-high gradient of calcium. In addition, calcium is an important second messenger that plays a key role in the regulation of pollen tube elongation and guidance [9-11]. ROS (reactive oxygen species) are also involved in pollen tube initiation, polarized-growth and elongation. Despite their toxicities, ROS act as a second messenger and are localized at the

(C) The Author(s). 2019 Open Access This article is distributed under the terms of the Creative Commons Attribution 4.0 International License (http://creativecommons.org/licenses/by/4.0/), which permits unrestricted use, distribution, and 
pollen tube tip [12-14]. ROS production is partially associated with RBOH (respiratory burst oxidase homologs) a family of $\operatorname{NADP}(\mathrm{H})$ oxidases localized at the plasma membrane $[12,15]$.

During pollen tube growth, the cytoskeleton, mainly composed of actin microfilaments and microtubules, maintains the cytoplasm movements inside the pollen tube as the so-called "reverse fountain streaming". Microtubules are involved in the male germ unit (MGU) movement whereas actin microfilaments are implicated in organelle and vesicular trafficking as well as pollen tube growth [6]. The use of live-cell actin markers such as Lifeact-EGFP has confirmed the involvement and the spatial distribution of actin cables during pollen tube growth $[16,17]$. In the shank of pollen tubes, actin filaments follow an axial arrangement which allows organelle and vesicle transport to the tip. At the tip, actin filaments form a regular structure usually called actin fringe $[16,18-21]$. The actin fringe may contribute to the pectin-focused secretion in the apical cell wall by directing vesicles to specific sites of fusion at the extreme tube apex and contributing to the polarized growth of pollen tubes [22].

At the center of this process, ROP (RhO-related in Plant), a unique sub-family of Rho-GTPases in plants, is known to regulate tip-growth and polar cell expansion in different cell types, particularly the pollen-specific ROP1, is an essential regulator for pollen tip-growth [23-26]. ROP proteins are cytosolic and inactive in the GDP-bound state and are active when associated with the plasma membrane in the GTP-bound state. Guanine nucleotide exchange factors (GEFs) catalyze GDP release exchanged with GTP and GTPase activating proteins (GAPs) enhance GTP hydrolysis, inducing ROP inactivation [27]. ROP1 is localized in the plasma membrane of the pollen tube tip and has an oscillatory interaction with two downstream targets that are CRIB motif-containing ROP-interacting proteins (RIC3 and RIC4) [16, 28]. These two proteins have two distinct functions and control two different pathways downstream of ROP1: the formation of a tip-focused calcium gradient and the assembly of the actin fringe, respectively $[28,29]$.

Vesicles containing cell wall materials are transported by the reverse fountain streaming [30]. In Arabidopsis thaliana, pollen tubes possess a specific cell wall organization compared to somatic cells. In the shank, it is composed of an inner cell wall layer enriched in $\beta$-glucan (mostly callose and minor amount of cellulose) and an outer layer composed of cellulose, hemicellulose (mostly xyloglucan) and pectins including weakly methylesterified homogalacturonan (HG) and rhamnogalacturonan-1 $[31,32]$. Callose is not only present in the inner cell wall layer but also in plugs that are regularly synthesized allowing the vegetative cell to conserve a regular volume during pollen tube elongation [33, 34]. The mode and pattern of callose plug deposition vary among the species $[35,36]$. At the tip, only one cell wall layer is present and is enriched in methylesterified HG rhamnogalacturonan-1, arabinogalactan proteins (AGPs) and xyloglucan while it contains little amounts of cellulose [31, 32].

Despite the central role of pollen tubes during sexual plant reproduction leading to the production of high numbers of healthy seeds, this tip-growing cell represents also a very good model for studying polarized growth and cell wall synthesis and remodeling $[8,32,37-40]$.

For many years, different approaches were used to understand the complex processes involved in pollen tube growth and cell wall remodeling including functional genomics, enzyme and pharmacological treatments [41-44]. Recently, chemical screens of small compounds found significant applications in plant cell biology, mostly in relation with hormonal signaling (e.g., auxin, brassinosteroid or strigolactone) [45-48], and plant-pathogen interactions $[49,50]$. However only few studies were conducted on pollen. An automated image-based screen was developed for compounds that inhibited pollen germination in vitro or affected polar growth [51]. Pollen tubes were also used to understand plant growth and development [52] or cellular processes such as endomembrane trafficking [53].

In the present study, we screened 258 diverse compounds from the chemical library from CERMN (Centre d'Etudes et de Recherche sur le Médicament de Normandie, Normandie Univ, UniCaen, France), part of la Chimiothèque Nationale (http://chimiothequenationale.cn.cnrs.fr/) on A. thaliana pollen germination and pollen tube growth. Two compounds $t$ we named Disruptol-A and Disruptol-B were isolated. Together with galvestine-1, known to alter pollen tube growth and inhibit the biosynthesis of galactolipids through inhibition of monogalactosyldiacylglycerol (MGDG) synthases [54], these molecules were able to interfere with pollen germination and disrupt the polarized growth of the pollen tube in a dose-dependent manner by modulating actin dynamics and ROS accumulation. The distribution of cell wall polymers including callose, pectins and arabinogalactanproteins (AGPs) was also affected by the treatments suggesting that the compounds may directly or indirectly perturb vesicular trafficking at the pollen tube tip. Their dose-dependent effects point out the potential benefits of these compounds as new tools to study polarized growth.

\section{Results}

\section{Chemical screen identified two compounds from the} CERMN chemical library

Among the 258 diverse compounds tested at $20 \mu \mathrm{M}$ during the primary screen, two compounds were selected based on their abilities to distrupt the tip-polarized growth 
of $A$. thaliana pollen tubes. The compounds were named Disruptol-A and Disruptol-B (Fig. 1a). Even if Disruptol-A is a tricyclic furopyrrolodiazepinone and Disruptol-B a linear ureidothiophenecarboxylic acid, the two derivatives share common structural features (anisole pending ring, five-membered heterocycle, carboxamide or ureido group,

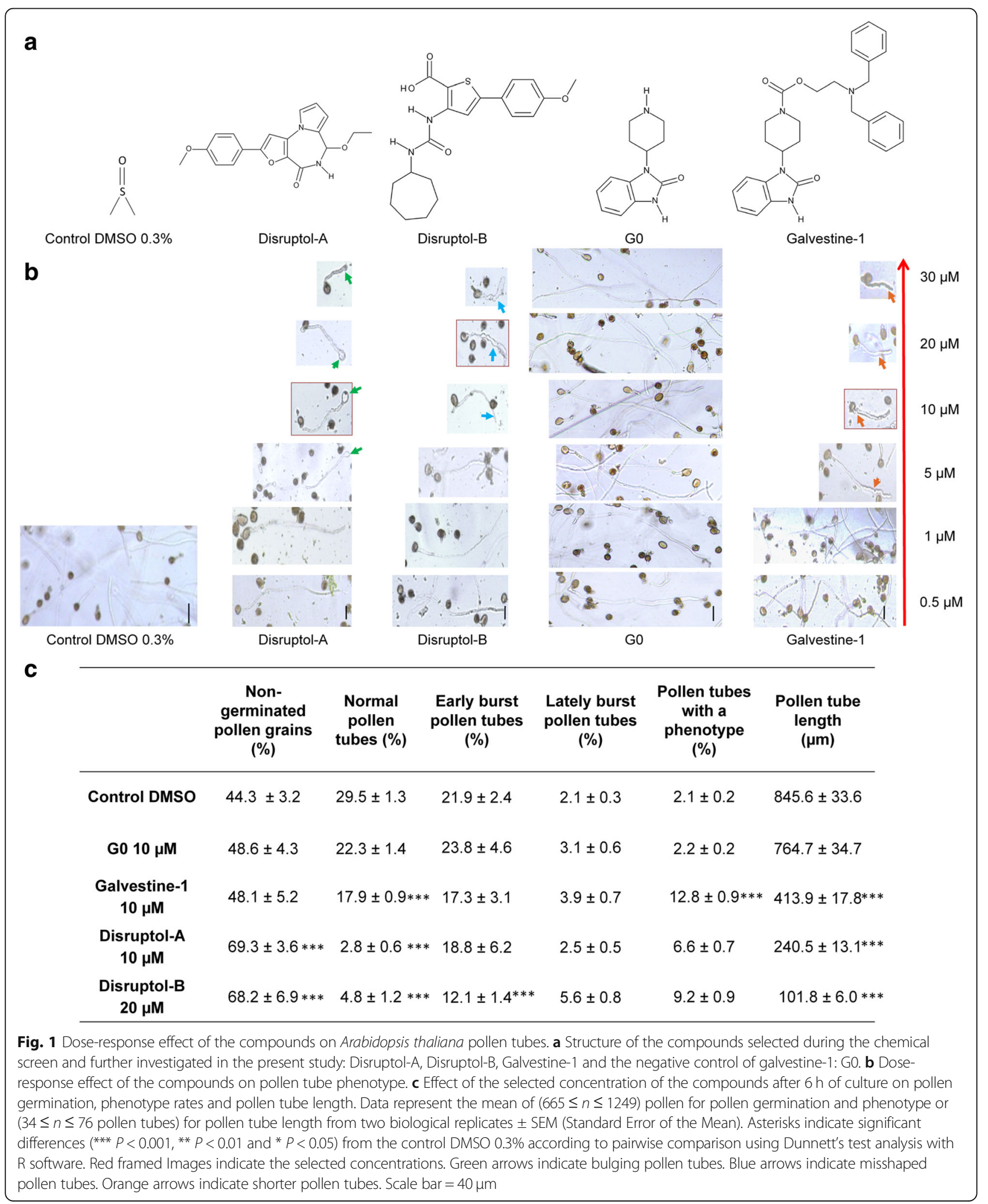


alkyl or cycloalkyl chain...) and Disruptol-A can be considered as a rigidified analog of Disruptol-B. Another compound (galvestine-1) was also used in this study (Fig. 1a). Galvestine-1 was shown to reduce pollen tube length in vitro [54] and was further characterized. The negative control of galvestine-1 is G0. G0 molecule possesses a galvestine-1 structure modification that leads to the loss of bioactivity (Fig. 1a) [54].

\section{Effects of the compounds on pollen germination and pollen tube growth}

The effect of the selected compounds on pollen germination and pollen tube growth was investigated in 96-well plates using Arabidopsis, tobacco and tomato pollen grains incubated for $6 \mathrm{~h}$ with the compounds at different concentrations (Fig. 1b, Additional file 1: Figure S1). Pollen tubes treated with $0.3 \%$ DMSO (control) had an average length of $845.6 \mu \mathrm{m} \pm 33.6$ (Fig. 1c). Similar results were obtained with different concentrations of the G0 (galvestine negative control). Both DMSO and G0 treatments did not show any changes neither on pollen germination nor on the shape and/or the length of the pollen tubes (Fig. 1b and c). The rates of normal pollen tubes ranged from $22.3 \% \pm 1.4$ to $29.5 \% \pm 1.3$ for $\mathrm{G} 0$ and the $0.3 \%$ DMSO, respectively and only $2 \%$ of pollen tubes displayed abnormal shape (Fig. 1c). Disruptol-A, Disruptol-B and galvestine-1 had a dose-dependent effect on pollen tube length (Fig. $1 \mathrm{~b}$ and c). After $6 \mathrm{~h}$, pollen tubes treated with Disruptol-A were shorter (Fig. 1c) and displayed a swollen tip above $5 \mu \mathrm{M}$ (Fig. 1b). The tubes reached only $400 \mu \mathrm{m}$ after $6 \mathrm{~h}$, half the length of the DMSO control (Fig. 1c). In the presence of Disruptol-B, pollen tubes were also shorter above $5 \mu \mathrm{M}$ (Fig. 1b). At $20 \mu \mathrm{M}$, pollen tubes were misshaped at the tip (Fig. 1b). Galvestine-1 also caused a significant reduction in pollen tube length at $10 \mu \mathrm{M}$ (Fig. 1c) but did not induce any strong deformation (Fig. 1b). Similar effects were observed on treated Solanum lycopersicum and Nicotiana tabacum pollen tubes (Additional file 1: Figure S1). To investigate further the effects of the compounds, only one concentration was selected and used for each based on the ratio between germination rates and the frequency of the phenotypes. Thus, the concentrations were selected to avoid severe effects (non-germinated, non-growing or dead pollen tubes) but to have viable and growing tubes with a phenotype. The selected concentrations (highlighted by red squares in Fig. 1b) were $10 \mu \mathrm{M}$ for Disruptol-A and galvestine- 1 and $20 \mu \mathrm{M}$ for Disruptol-B.

The early burst pollen tubes (i.e. pollen tubes bursting just after germination) did not change dramatically (22$24 \%$ in the controls and $17-19 \%$ with galvestine-1 and Disruptol-A except for Disruptol-B (12\%) (Fig. 1c). Treatment with $10 \mu \mathrm{M}$ galvestine-1 resulted in shortened pollen tube (12.8\%) and anincrease of the proportion of lately burst pollen tubes (i.e. burst of pollen tubes with a length equal to the pollen grain diameter $\sim 20 \mu \mathrm{m}$ ) (3.9\%) compared to the control G0. Treatments with Disruptol-A $(10 \mu \mathrm{M})$ and Disruptol-B $(20 \mu \mathrm{M})$ affected pollen tube germination. The rates of non-germinated pollen grains were $69.3 \% \pm 3.6$ with Disruptol-A and $68.2 \% \pm 6.9$ with Disruptol-B significantly higher than those of the control samples $(44.3 \% \pm 3.2)$. Similarly, the rates of normal pollen tubes with Disruptol-A and Disruptol-B were $2.8 \% \pm 0.6$ and $4.8 \% \pm 1.2$, respectively and significantly lower than in the control $(29.5 \% \pm 1.3)$ (Fig. 1c).

Finally, all the compounds have a significant effect on the pollen tube diameter. The diameters of the tubes were measured at 5 and $30 \mu \mathrm{m}$ back from the tip (Fig. 2). The pollen tube diameters in the controls were between 5 and $7 \mu \mathrm{m}$ (Fig. 2). After $6 \mathrm{~h}$ of incubation with galvestine-1, pollen tube diameters increased significantly at $5 \mu \mathrm{m}$ and $30 \mu \mathrm{m}$ from the tip, reaching $9.2 \mu \mathrm{m} \pm 0.4$ and $12.6 \mu \mathrm{m} \pm 0.5$, respectively. Disruptol-B treatment induced also a significant increase of the pollen tube diameters but only at $30 \mu \mathrm{m}$ from the tip $(9.9 \mu \mathrm{m} \pm 0.5)$. Disruptol-A has the most important effect on the diameters of pollen tubes reaching around $16 \mu \mathrm{m}$ at 5 and $30 \mu \mathrm{m}$ back from the tip (Fig. 2), due to the swelling of the tip (Fig. 1b).

\section{Effect of the compounds on superoxide production}

To determine the effect of the compounds on superoxide production, we used NBT staining. NBT allows to detect the superoxide anion $\left(\mathrm{O}_{2}{ }^{\circ}\right)$ after $20 \mathrm{~min}$ of incubation with the reagent. NBT staining was quantified using Image J software as the mean pixel intensity in the pollen tube tip (Fig. 3). Under the two control conditions (DMSO and G0), the accumulation of superoxide regularly increased after 2, 4 and $6 \mathrm{~h}$ (Fig. 3) and the pixel mean intensity slightly increased over time: 184 , 224 and 230 after 2,4 and $6 \mathrm{~h}$ respectively for the DMSO and 150, 197 and 230 after 2, 4 and $6 \mathrm{~h}$ respectively for G0 (Fig. 3). Galvestine-1 induced the same increase with no significant difference compared to the control (Fig. 3). Treatments with Disruptol-A and Disruptol-B showed no significant differences after 2 and $4 \mathrm{~h}$ when compared to the DMSO (Fig. 3). However, after $6 \mathrm{~h}$, the anion superoxide production was significantly lower in the treated samples $(158.7 \pm 0.12$ for Disruptol-A, $177.5 \pm 0.04$ for Disruptol-B) than in the DMSO (229.89 \pm 4.29$)$ (Fig. 3).

\section{Effect of the compounds on cell wall deposition}

To investigate the effect of the compounds on the number of callose plugs and callose deposition in the cell wall, we used decolorized aniline blue (DAB) (Fig. 4a). It is important to note that pollen tubes grown for $2 \mathrm{~h}$ in 


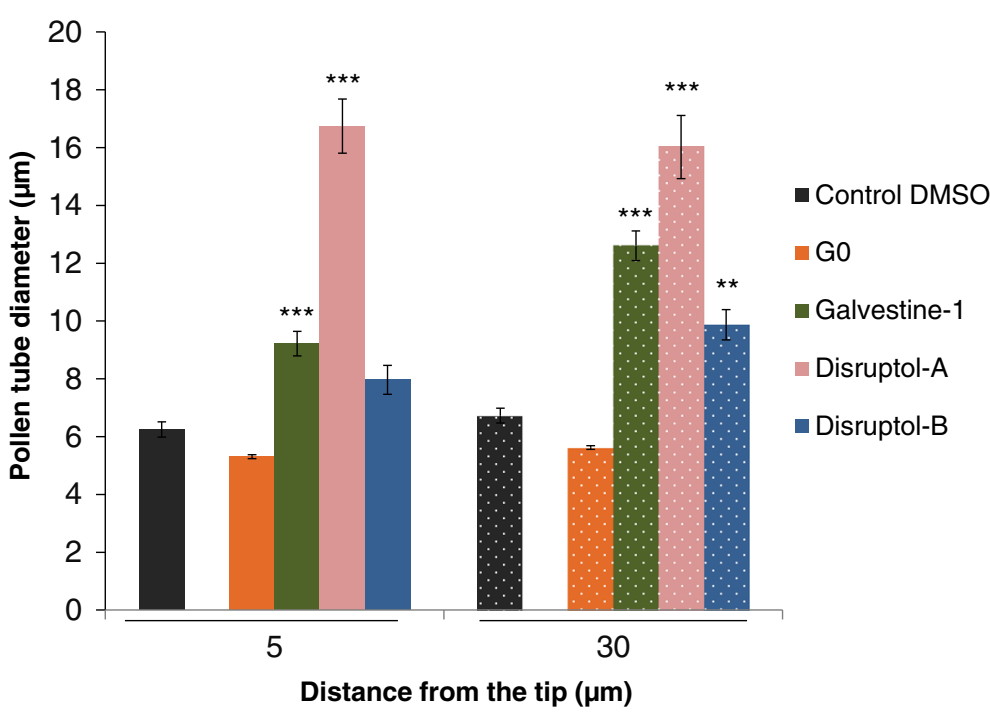

Fig. 2 Effect of the selected concentrations of the compounds on pollen tube diameters at $5 \mu \mathrm{m}$ and $30 \mu \mathrm{m}$ from the tip. Data represent the mean of 15 pollen tubes from two biological replicates \pm SEM. Asterisks indicate significant differences $\left(* * *<0.001,{ }^{* *} P<0.01\right.$ and $\left.{ }^{*} P<0.05\right)$ from the control DMSO 0.3\% according to Dunnett's test analysis with R software

the control conditions (DMSO and G0) were added to the data set in order to be able to compare the number of callose plugs in short tubes (i.e. $6 \mathrm{~h}$ of growth for treated pollen tubes). Pollen tubes grown for $2 \mathrm{~h}$ with DMSO and G0 were less than $500 \mu \mathrm{m}$ long and for most of them $(\sim 90 \%)$, they produced one callose plug (Fig. 4b). After $6 \mathrm{~h}$, control pollen tubes showed normal callose deposition in the cell wall and plugs (most of them contained 2 plugs, the remaining pollen tubes had 1 or 3 callose plugs and only few $<5 \%$ had 4 callose plugs) (Fig. 4b). The first callose plug was close to the pollen grain (Fig. 4a), the other ones were regularly deposited and their numbers increased with the gain of pollen tube length (Fig. $4 \mathrm{~b}$ ).

When pollen tubes were treated with Disruptol-A, the length of pollen tubes ranged between 48 and $579 \mu \mathrm{m}$ and contained $0-1$ callose plug for $98.6 \%$ of them (Fig. 4b). Treatment with Disruptol-B induced a decrease of the pollen tube length $(200 \mu \mathrm{m}$ maximum $)$ but the tubes still contained up to 1 callose plug (Fig. 4b). It is relevant to note that, in certain cases, galvestine- 1 , Disruptol-A and Disruptol-B treatments induced also

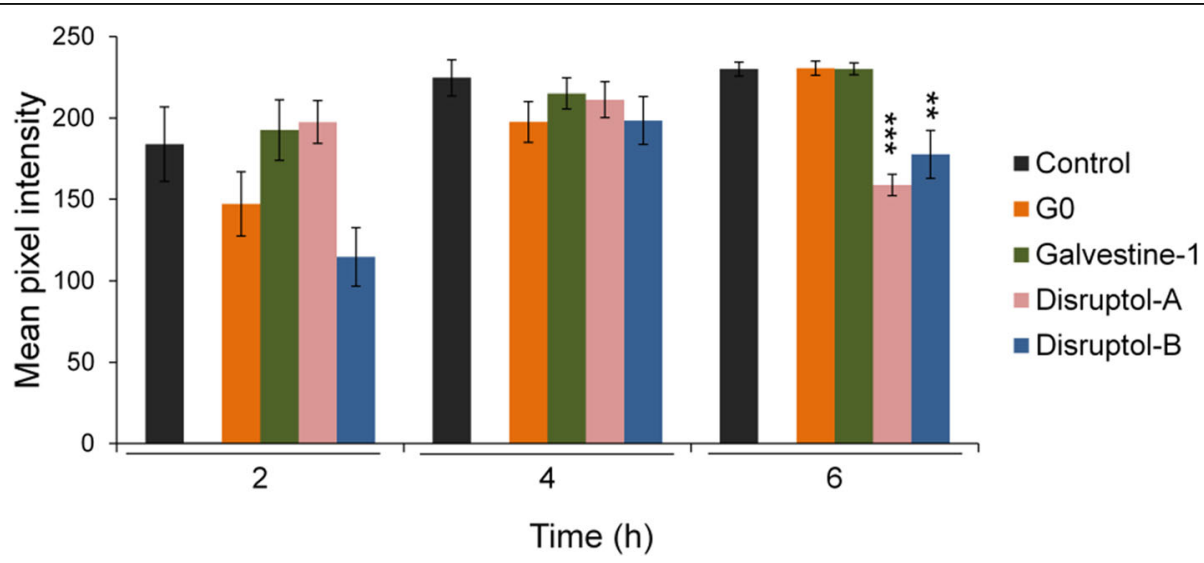

Fig. 3 Effect of the compounds on anion superoxide (O2-) production. Mean pixel intensity of NBT staining after 2, 4 and $6 \mathrm{~h}$ of treatment. For mean pixel intensity, pictures were transformed as grayscale images, a mark was drawn from the tip to $30 \mu \mathrm{m}$ behind and the region of Interest, $\mathrm{ROI}$, was manually selected using freehand selection tool. The mean value of the pixel intensity was obtained with the measure tool of the Image J software. Data represent the mean of ( $6 \leq n \leq 14$ pollen tubes) from 2 biological replicates \pm SEM. Asterisks indicate significant differences (** $P<0.001,{ }^{* *} P<0.01$ and $* P<0.05$ ) from the control DMSO $0.3 \%$ according to pairwise comparison using Dunnett's test analysis (for $2 \mathrm{~h}$ and $4 \mathrm{~h}$ ) and according to pairwise comparison using Wilcoxon's test analysis with Holm adjustment (for $6 \mathrm{~h}$ ) with $\mathrm{R}$ software according to parametric and non-parametric batch of time dataset 


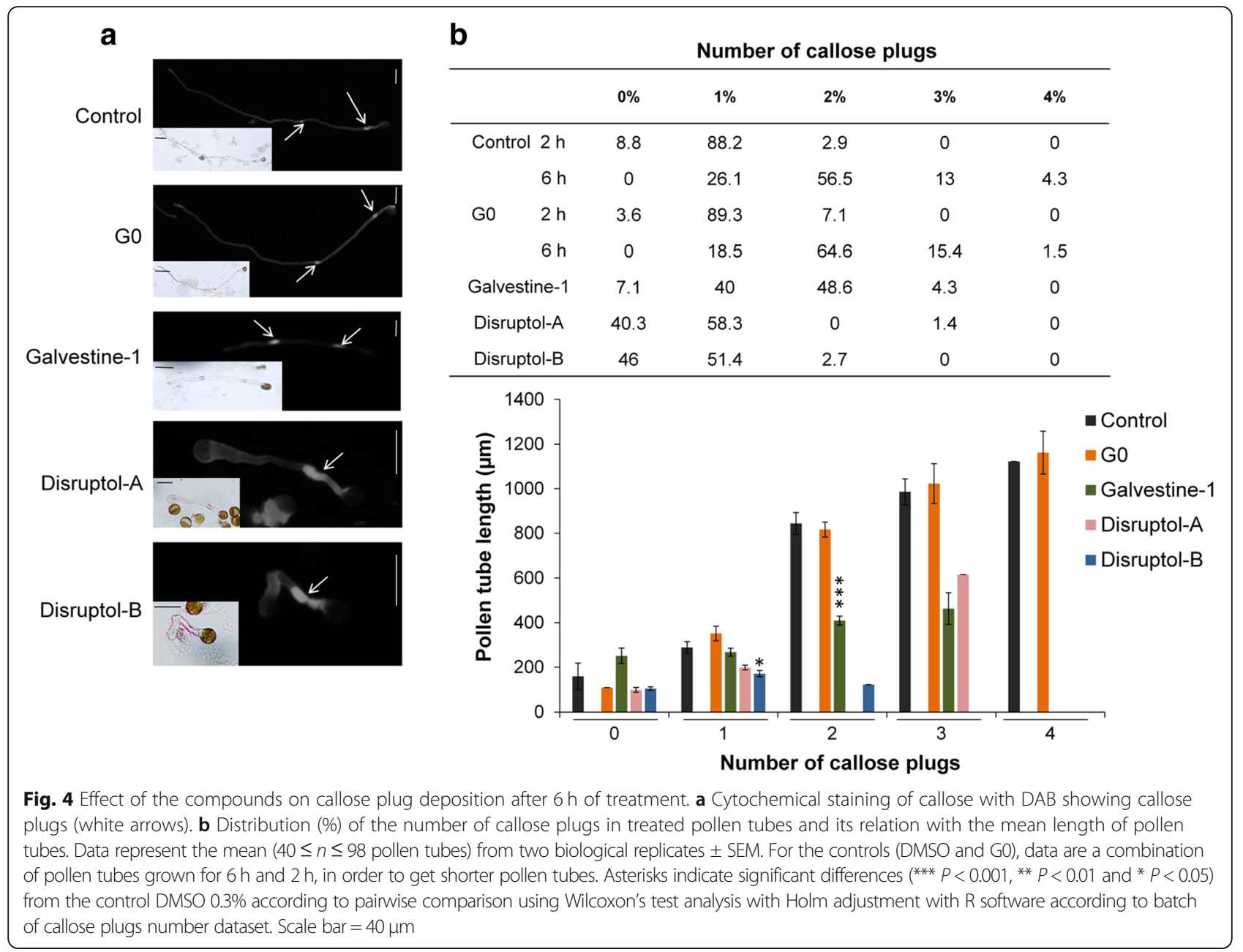

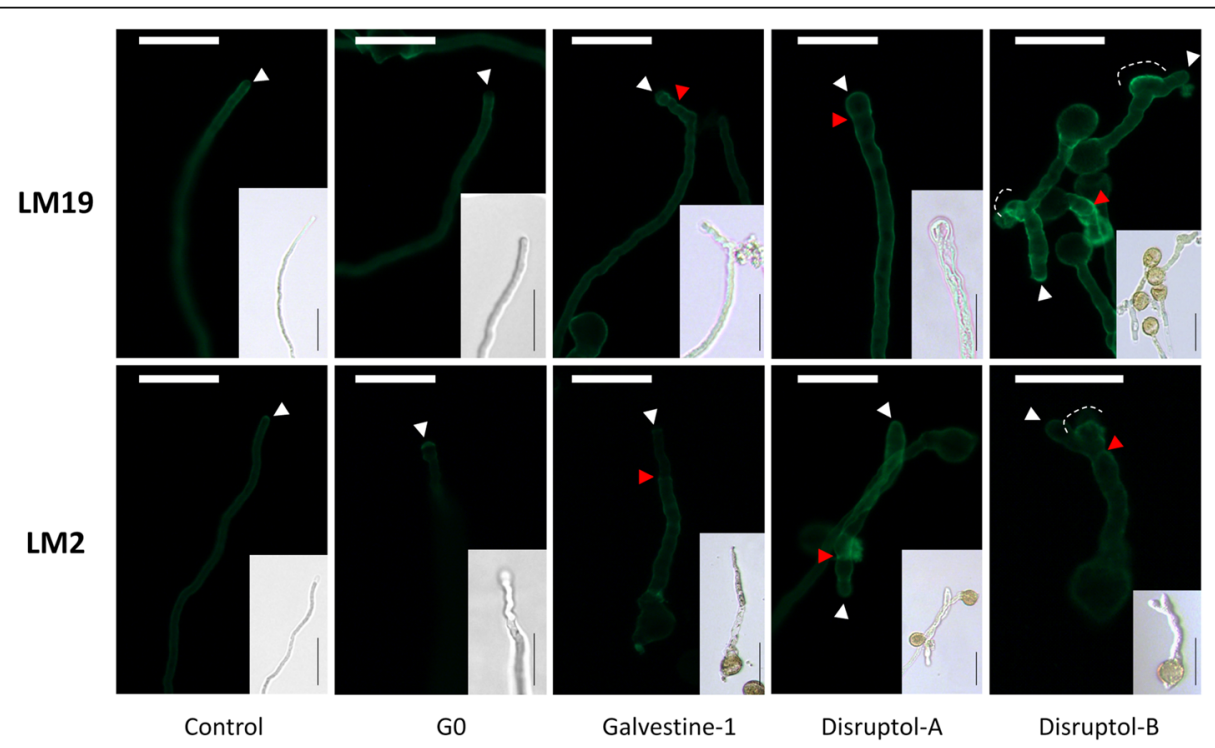

Fig. 5 Cell surface immuno-labeling of epitopes associated with weakly methylesterified homogalacturonan and arabinogalactan proteins using LM19 and LM2, respectively on pollen tubes treated with the compounds for $6 \mathrm{~h}$ from 2 biological replicates. White arrow head = pollen tube tip, red arrowhead $=$ ring-like deposit and dashed white line = pollen tube deformation. Scale bar $=40 \mu \mathrm{m}$ 
callose deposition in the cell wall at the tips of the tubes for $0.7,7.5$ and $2.7 \%$, respectively. This pattern of deposition was absent in the controls. Pollen tubes treated with galvestine-1 were shorter than in G0 but still contained a high number of callose plugs between 1 and 3 for tubes reaching 200 and $400 \mu \mathrm{m}$, respectively (Fig. 4b). For the same average length $(\sim 400 \mu \mathrm{m})$, pollen tubes treated with galvestine- 1 contained 2 (for most of them) or 3 plugs.

Immunolabelling of pollen tubes with the LM19 antibody (Fig. 5), which recognizes low methylesterified HGs, revealed that this epitope was mostly detected in the shank of pollen tubes in the control conditions (DMSO and G0). The treated pollen tubes showed different distributions of this epitope. $85 \%$ of pollen tubes treated with galvestine- 1 showed a localization at the tip, compared to the control (14\%). For $100 \%$ of those treated with Disruptol-A, the epitope recognized by LM19 was localized in the entire pollen tube cell wall and $92 \%$ for the pollen tubes treated with Disruptol-B. A brighter labelling was also observed in pollen tube distortion zones which originally were the expanding tip that stopped to grow leading to the emergence of a new tip. With all the treatments, brighter ring-like deposits were also observed and in the swollen tips of pollen tubes treated with Disruptol-A suggesting an accumulation of cell wall material during the slow growth phases.

Immunolabelling with the LM2 antibody, which recognizes epitopes associated with AGPs, revealed that this epitope was brightly labelled at the tip of control pollen tubes (DMSO and G0). 93.7\% of pollen tubes treated with galvestine- 1 and $100 \%$ of pollen tubes treated with Disruptol-A did not show a brighter labeling at the tip compared to the control (20\%). All the treatments also induced brighter ring-like deposits along the pollen tube cell wall as observed with LM19.

\section{Effect of the compounds on actin dynamics and RIC4, a tip-polarized marker}

To investigate whether the miss-localization of the cell wall polymers and the growth defect were due to a disruption of the intracellular trafficking, actin filament dynamics was followed using pollen tubes expressing pLAT52::lifeact-mEGFP. In the controls (DMSO and G0), after 2, 4 and $6 \mathrm{~h}$ of incubation, actin dynamics was normal with long cables observed in the shank region of the pollen tube and the actin fringe at the tip (Fig. 6; Additional file 2: Figure S2; Additional file 3: Video S1). These structures remained highly dynamics and pollen tubes were expanding normally overtime (Additional file 2: Figure S2). After $4 \mathrm{~h}$ and $6 \mathrm{~h}$ of treatment with Disruptol-A, vacuoles that are normally located in the back of the pollen tube were clearly visible in the tip region (Fig. 6, Additional file 2: Figure S2, Additional file 4: Video S2) and the actin fringe begun to disappear with the appearance of the swollen tip and was totally absent after $6 \mathrm{~h}$ of incubation (Fig. 6). At this time, pollen tubes were not expanding anymore but actin cables were still moving (Additional file 2: Figure S2). After 2, 4 and $6 \mathrm{~h}$ of incubation with Disruptol-B, the actin fringe and the spatial organization of actin filaments also looked abnormal (Fig. 6). However, after 4 and $6 \mathrm{~h}$, pollen tubes were still expanding but more slowly than the control and in a winding way (Additional file 2: Figure S2; Additional file 5: Video S3) and no vacuoles were detectable at the tip (Fig. 6; Additional file 2: Figure S2). After $2 \mathrm{~h}$ and 4 $\mathrm{h}$ of incubation with galvestine-1, pollen tubes were also expanding but after $6 \mathrm{~h}$, the growth was reduced (Additional file 2: Figure S2). After $4 \mathrm{~h}$, the shape of the actin fringe changed with the increasing size of the pollen tube diameter. It was located in the subapical region and at the beginning of the shank region. After $6 \mathrm{~h}$ of treatment, the actin fringe was more detectable in the apex and disappeared from the shank region and the subapical region (Fig. 6). Small punctates of actin foci were also observed in the shank close to the apical region only in pollen tubes treated with galvestine-1. Disruptol-A and galvestine-1 treatments induced the appearance of actin rings after 4 and $6 \mathrm{~h}$ of incubation in the shank region. Actin rings were also observed in pollen grains treated with Disruptol-B. Actin rings were not observed in the pollen tubes of the control and G0 (Fig. 6).

The effect of the compounds on ROP1, an apical growth marker, was assessed by following the location of RIC4, an effector protein of ROP1 using $p C L:: C R I B 4-G F P$. In the controls (DMSO and G0), RIC4 localization remained normal after 2, 4 and $6 \mathrm{~h}$ of growth (Fig. 6) with pulsatile appearance/disappearance at the plasma membrane in the apical dome (Additional file 6: Figure S3). Under all conditions and in all pollen tubes, GFP was detected in the cytoplasm.

After $2 \mathrm{~h}$ of treatment with Disruptol-A, a perturbation of RIC4 dynamics was observed. RIC4 was not only localized at the apical dome but also in the subapical region and sometimes this location was persisting (Fig. 6; Additional file 6: Figure S3). After $4 \mathrm{~h}$ of incubation, RIC4 localization disappeared from the apical plasma membrane and GFP was only located in the cytoplasm (Fig. 6). RIC4 localization at the tip of pollen tubes treated with Disruptol-B was extremely versatile and depended on the pollen tube shape. RIC4 was localized in the subapical region and then moved from one side to the other side of the apical dome of the pollen tube. This was associated with a slow growth and multiple changes of the tip growth direction (Fig. 6 and Additional file 7: Figure S4).

After 2 and $4 \mathrm{~h}$ of treatment with galvestine-1, RIC4 was located, as in DMSO and G0 conditions, in the 


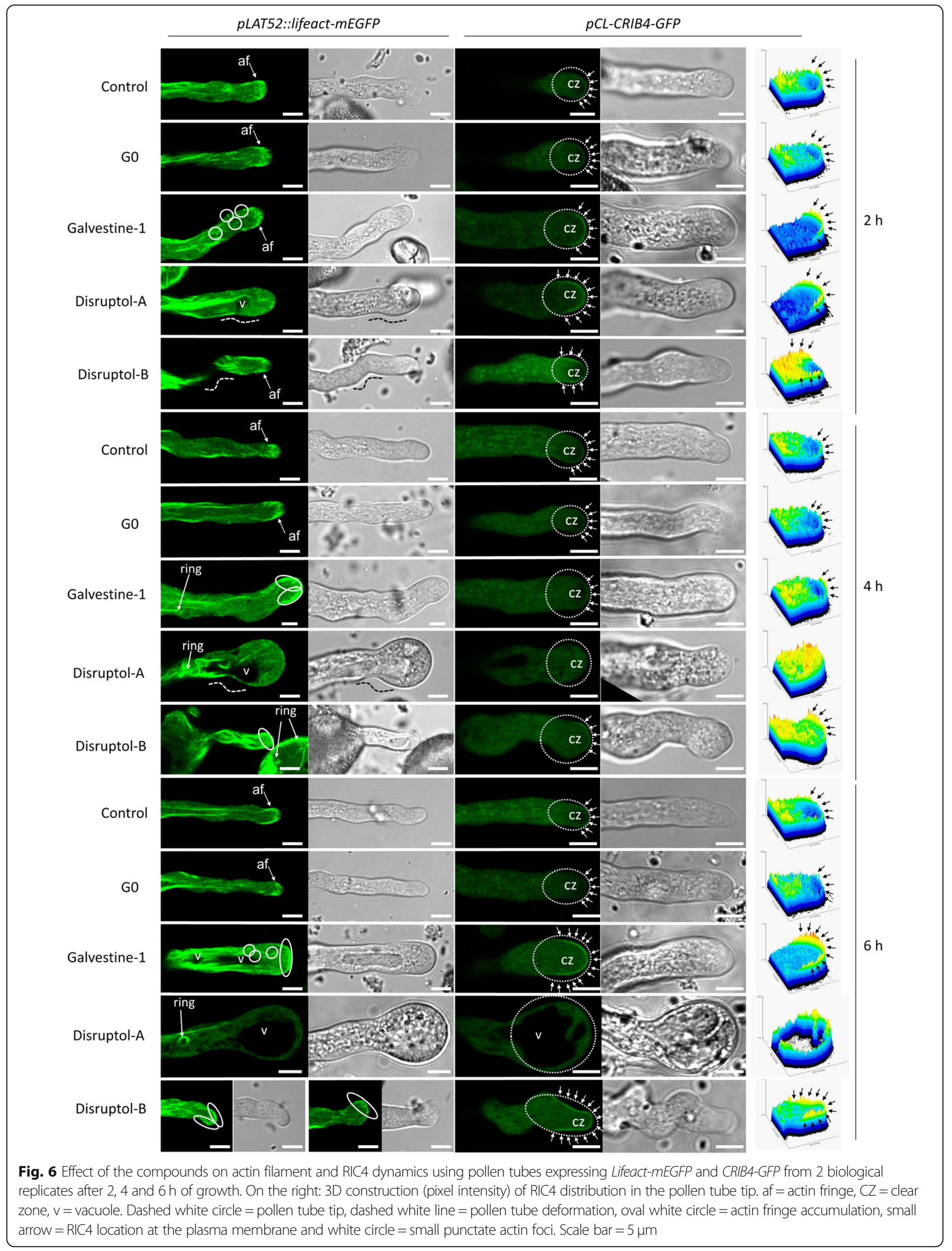


apical region (Fig. 6). The location was expanded to the subapical region after $6 \mathrm{~h}$ of treatment with galvestine-1 (Fig. 6).

\section{Discussion}

The compounds disrupt actin dynamics and ROP signaling: two central mechanisms in pollen tube tipgrowth

The actin cytoskeleton plays a critical role in pollen tubes and polar growth [19] and the treatments with galvestine-1, Disruptol-A and Disruptol-B were able to disrupt actin cytoskeleton dynamics. Treatment with Disruptol-A induces a progressive disappearance of the actin fringe which completely disappears after $6 \mathrm{~h}$ and the appearance of the phenotype and pollen tube growth reduction. Similar effects were observed with the membrane trafficking inhibitor Brefeldin A (BFA) or with the electron transport chain inhibitor potassium cyanide $(\mathrm{KCN})[22,55]$. The treatments with Disruptol-B and galvestine-1 did not induce the disappearance of the actin fringe but led to a disruption of the structure. The instability of the actin fringe with Disruptol-B treatment may explain the winding shape of the pollen tube. Indeed, it was shown that the turnover of actin filaments (polymerization/depolymerization) was an early event for pollen tube directional growth changes [56].

All the treatments induced ring-shaped actin structures in the shank of pollen tubes. These structures that represent a circular conformation of actin filaments were observed in most pollen tubes and were already described in several studies using either staining techniques or expressing fluorescent protein-tagged actin-binding domains [57-62]. Even if the high level of Lifeact expression can induce artefact due to the competition with native actin binding proteins $[59,63]$, it is possible that the ring-shaped actin structures in treated pollen tubes reflect a certain physiological state in the cell such as heat stress, calcium availability and extracellular $\mathrm{pH}$ changes $[60,64]$.

All treatments disturb RIC4 location and oscillation compared to the control. In pollen tubes treated with Disruptol-A, RIC4 completely disappeared from the apical region and this was accompanied by the disappearance of the actin fringe. These results are correlated with the fact that RIC4 pathway promotes the assembly of the actin fringe at the tip of the pollen tube [28].

Galvestine-1 is an inhibitor of the biosynthesis of galactolipids, more precisely MGDG. These galactolipids are critical for the biogenesis of photosynthetic membranes, and they act as a source of polyunsaturated fatty acids for the whole cell in phosphate shortage [54]. The expression of genes involved in galactolipid synthesis was shown to be strongly activated during pollen development and germination suggesting their importance during pollen maturation and pollen tube growth [65].
Galactolipids are present all along the membrane of pollen tubes [54] and inhibiting the biosynthesis of galactolipids may affect the plasma membrane ROP signaling/location. Interestingly, small and rare punctate actin foci were observed with galvestine-1 treatment. These structures are unusual and poorly described in the literature. Nevertheless, it appears that actin foci are induced during self-incompatibility (SI) response in Papaver [66] and are able to change the intracellular location of two actin-binding proteins, cyclase-associated protein and actin-depolymerizing factor [67]. Therefore, we postulate that the lipid homeostasis changes at the plasma membrane caused by galvestine- 1 , alter ROP1 and actin localization and dynamics [23-26, 68]. Thus, the disruption of actin filaments and dynamics by the treatments may result from an inhibition or an activation of actin binding proteins (ABPs) which play a crucial role in actin polymerization and depolymerization. In fact, the construction of actin structures requires several ABPs [58] such as formin, an actin-nucleating protein, implicated in establishing the subapical actin [69] or villin, a major bundling factor stabilizing actin filaments [55].

\section{The compounds disturb cell wall distribution and lead to a modification of pollen tube morphology}

The number of callose plugs is generally correlated with the length of pollen tubes [36, 70]. Treatment with LatB (Latrunculin B), an inhibitor of actin polymerization, affects callose plug deposition in pollen tubes and induces callose deposits at the tip. Based on the location of the callose, it has been postulated that LatB may trigger a stimuli response that enhances callose synthesis by activating callose synthases located at the tip [71]. In our experiments, when pollen tubes are treated with galvestine-1, Disruptol-A or Disruptol-B, the pollen tube length is not correlated with the number of callose plugs. In fact, the pollen tube length decreases but the number of callose plugs remained unchanged, suggesting that callose plugs are not pollen tube length-dependent but are synthesized in a time-dependent manner. But this needs further investigation. Even if actin filaments are critical for the distribution of callose synthases [34] and that previous studies have demonstrated that a disorganized cellulose synthase complex in the plasma membrane may be capable of catalyzing the synthesis of both cellulose and callose [72, 73], it is difficult to link the effect of our molecules to callose plugs formation or deposition. The synthesis of callose at the tip may be a protective mechanism of the pollen tube to recover from the treatment as shown/suggested with the emergence of new tip on treated pollen.

The appearance of the phenotype, especially with Disruptol-A and Disruptol-B treatments, and the inhibition/reduction of the elongation suggest that the cell 
wall deposition is affected by the treatments. In untreated pollen tubes, weakly methylesterified HG epitopes are mostly present in the shank but not at the tip, in contrast arabinogalactan protein-associated epitopes are more detectable at the tip. These results are in agreement with previous studies [31, 32, 74, 75]. It is generally established that pectins are secreted highly methyesterified at the extreme apex, and are then de-esterified through the activity of pectin methylesterases within the cell wall [76]. This tight regulation is thought to control the stiffness of the cell wall between the tip (extensibility) and the shank (rigidity) to sustain the cylindrical shape of the tube [77, 78]. All the treatments show an abnormal tip localization of LM19 antibody binding. Pectin remodeling might thus be affected by the treatments impacting the capacity of the pollen tube cell wall extension [37, 71, 79]. The absence of tip-localized labelling of AGPs in the presence of Disruptol-A and galvestine-1 confirmed that cell wall material delivery was altered as AGPs are assumed to be involved in the deposition of new cell-wall material during pollen-tube growth [74, 75]. As actin cytoskeleton is important for vesicle trafficking, the modification of the cell wall polymer distribution is possibly related to an alteration of vesicular transport and polarized exocytosis of cell wall polymers and cell wall-modifying enzymes [80-82]. Blocking AGPs at the plasma membrane surface of pollen tubes by treatment with the Yariv phenylglucoside also induced callose deposition at the tip, mislocation of AGPs and pectins along with growth arrest
$[74,83]$. Interestingly, the effect was reversible upon removal of the reagent and a new emerging tip could be produced back from the original tip that was blocked [74] as it is observed with Disruptol-B.

Besides their role as second messenger in countless physiological processes often associated with cytotoxicity [84-87], ROS are also known to act on wall plasticity [88] and are implicated during pollen tube growth $[12,13]$. During this study, ROS production was assessed using NBT, which reacts specifically with $\mathrm{O}_{2}{ }^{\circ-}$. The production of $\mathrm{O}_{2}{ }^{*-}$ significantly decreased only with Disruptol-A and Disruptol-B (Fig. 3). $\mathrm{O}_{2}{ }^{*-}$ plays a role in pollen tube growth and reorientation [12, 89]. ROS may also play a role in influencing actin polymerization dynamics in plant cells [90]. We can hypothesize that the disruption of the $\mathrm{O}_{2}{ }^{*-}$ production by Disruptol-A and Disruptol-B can then induce actin dynamics disruption. The compounds used in this study affect more clearly the actin-fringe. As with $\mathrm{KCN}$, the fringe is among the first components to degrade together with the loss of the clear zone and the inhibition of growth, but with a continuation of cytoplasmic streaming [22]. ROS are known to also play roles in modulating cell wall extensibility to allow expansion but also to prevent tip bursting [91]. Following Disruptol-A and Disruptol-B treatments, the decrease of $\mathrm{O}_{2}{ }^{--}$level induces tip swelling and the loss of polarity, probably by altering the balance between different forms of ROS that promotes cell wall stiffening and/or loosening [92].

However, the links between the modification of polarized growth, the remodeling of cell wall polymers
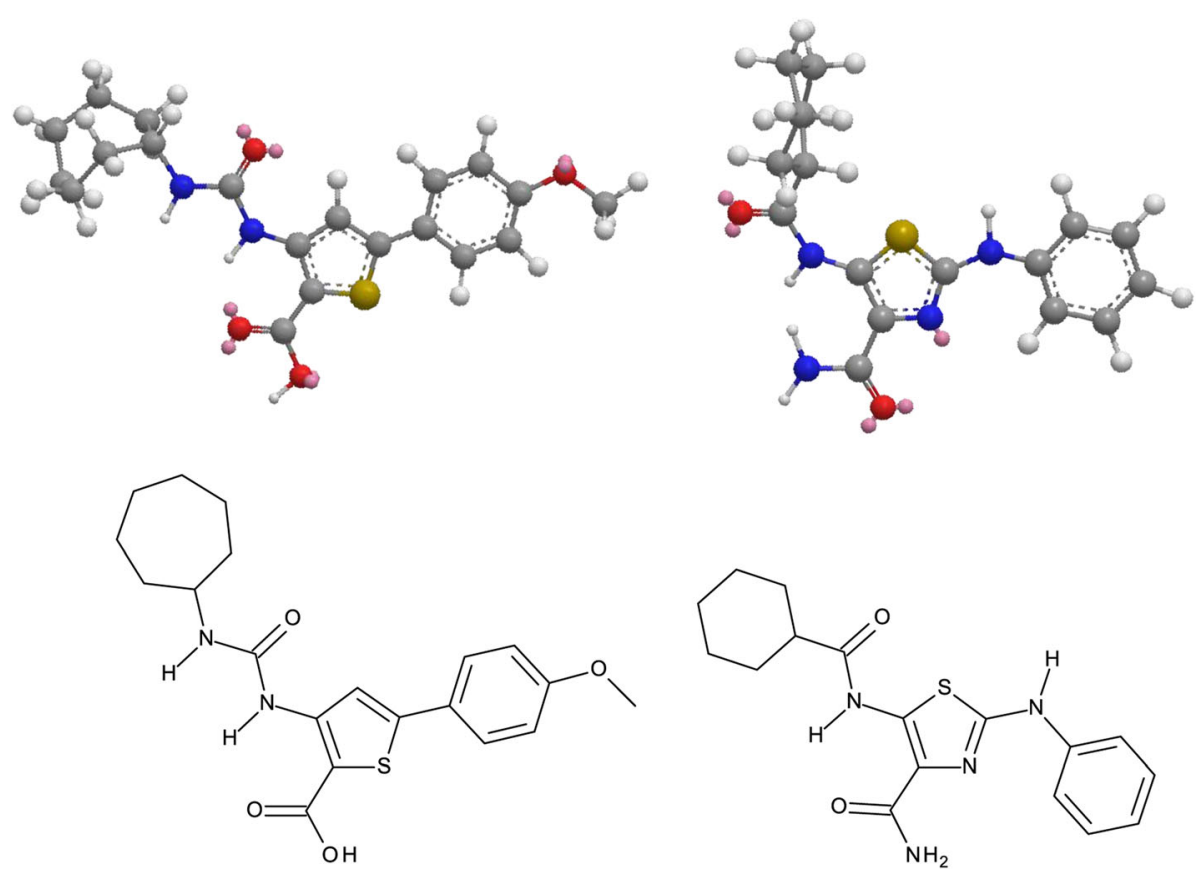

Fig. $73 D$ and 2D representations of Disruptol-B (Left) and UNC-3230 (right) 
and actin dynamic remain unclear and will await further investigation.

\section{Conclusion}

Possible targets for Disruptol-A and Disruptol-B

The targets of Disruptol-A and Disruptol-B are currently unkown. Disruptol-A and Disruptol-B are two synthetic compounds from the CERMN's chemolibrary. From a structure-activity relationship (SAR) point of view, Disruptol-A and Disruptol-B theoretically exhibit appropriate structural features to engage inhibitory interactions with kinases as illustrated by the molecules, ureidofurane and thiophene carboxamides known to interfere with the inhibitor of nuclear factor kappa-B kinase (IKK) [93]. More specifically, the pharmacophoric features of Disruptol-B are closely related to those present in the structure of UNC3230, a PIP5K inhibitor (Fig. 7) [94] and this lipid kinases family could be potential targets for our compounds. Further investigations are required to verify this hypothesis and determine the direct and indirect effects of Disruptol-A and Disruptol-B on the tipgrowth machinery.

Phosphoinositides together with actin dynamics are crucial for maintenance of vacuole morphology [95]. Recently, Arabidopsis vac14 loss-of-function mutant, deficient in AtVAC14, a homolog of the yeast and metazoan VAC14 was implicated in the synthesis and turnover of Phosphatidylinositol 3-5 bi-phosphate (PI(3-5) $\mathrm{P}_{2}$ ) was characterized [96]. In Arabidopsis, VAC14 is constitutively and strongly expressed in developing pollen and its loss leads to pollen abortion and pollen tube growth defect [96]. Moreover, treatment of pollen tubes with the cell permeable inhibitor of PIPkinase, YM-201636, induced similar defects as observed with the treatments with Disruptol-A and B i.e. reduction of pollen germination and shorter tubes with wider diameter [96]. Similarly, overexpression in tobacco pollen tubes of PIP5K10 or PIP5K11, two pollen specific phosphatidylinositol-4-phosphate (PI4P) 5-kinases, able to produce in vitro phospholipid phosphatidylinositol-4,5-bisphosphate resulted in severe tip swelling, vacuolization and altered actin fine structure [97]. We might then hypothesized that Disruptol-A interferes with phosphoinositide metabolism in pollen tubes perturbing the actin cytoskeleton which can be influenced by PI4P 5-kinases and possibly contributing to the control of the pool of plasma membrane-associated Nt-Rac5. In fact, Nt-Rac5 is a member of the small GTPase family implicated in actin reorganization during cell growth [98]. Orthologs named ARAC4/ROP2, ARAC1/ROP3, ARAC6/ROP5, ARAC11/ROP1 and ARAC3/ROP6 are found in the Arabidopsis genome and ARAC11/ROP1 have been implicated in pollen tube growth [29]. The disruption of RIC4 location with Disruptol-B and galvestine-1 treatments is also accompanied with the disorganization of the actin fringe. RIC4 oscillates from the tip to the sub-apical tip region and its location predicts pollen tube directional growth suggesting that the abnormal localization of RIC4 in the apical region explains the multi-directional growth of pollen tubes [28]. Although, it remains unclear whether RIC4 directly or indirectly interacts with actin filaments by regulating actin polymerization factors [98], our results showed that disruption of RIC4 dynamics is closely related to the formation of the actin fringe and confirmed that apical filamentous actin dynamics and concentrations are influenced by ROP-GTPases [27].

\section{Methods}

\section{Plant growth conditions}

Seeds of $A$. thaliana Col-0 (stored at $4{ }^{\circ} \mathrm{C}$ ) were spread on the surface of sterilized soil and cultivated in growth chambers in long-day photoperiod $(16 \mathrm{~h}$ light $/ 8 \mathrm{~h}$ dark at $20{ }^{\circ} \mathrm{C} / 16^{\circ} \mathrm{C}$, respectively) and $60 \%$ relative humidity. Seeds containing the $p L A T 52::$ ifeact-mEGFP $[17,99]$ or $p C L-C R I B 4-G F P$ [100] constructions were a gift of Pr. Shanjin Huang (Institute of Botany, Chinese Academy of Sciences, Beijing, China) and Pr. Zhenbiao Yang (Center for Plant Cell Biology, University of California, Riverside, USA), respectively.

Nicotiana tabacum cv. Xanthi seeds were spread on the surface of sterilized soil. Plants were grown with a photoperiod of a $16 \mathrm{~h}$ light $/ 8 \mathrm{~h}$ dark cycle at 25 and $22^{\circ} \mathrm{C}$ during the light and dark period, respectively. Relative humidity was maintained at $60 \%$, and plants were watered every 2 d. Tobacco seeds were a gift from UMR 6037 (CNRS, Université de Rouen, Rouen, France).

Solanum lycopersicum var. cerasiforme 'West Virginia 106' (wva106) seeds were sown $1 \mathrm{~cm}$ under the surface of sterilized soil and cultured in a growth chamber. Plants were grown with a photoperiod of a $16 \mathrm{~h} \mathrm{light} / 8 \mathrm{~h}$ dark cycle at 25 and $22{ }^{\circ} \mathrm{C}$ during the light and dark period, respectively. Relative humidity was maintained at $60 \%$, and plants were watered every $2 \mathrm{~d}$. Tomato seeds were a gift from Dr. Pierre Baldet (INRA, Université de Bordeaux, UMR 1332, Bordeaux, France).

\section{Pollen tube culture}

Pollen grains of $A$. thaliana were germinated in liquid germination medium (GM) containing $5 \mathrm{mM} \mathrm{CaCl} 2$ $2 \mathrm{H}_{2} \mathrm{O}, 0.01 \%(w / v) \mathrm{H}_{3} \mathrm{BO}_{3}, 5 \mathrm{mM} \mathrm{KCl}, 1 \mathrm{mM} \mathrm{MgSO}{ }_{4} 7$ $\mathrm{H}_{2} \mathrm{O}$, and $10 \%(\mathrm{w} / \mathrm{v})$ sucrose, $\mathrm{pH} 7.5$ as described previously [101]. As recommended by [102], 40 fully open flowers collected in the second row from the top of the primary and secondary inflorescences (in $1.5 \mathrm{~mL}$ Eppendorf ${ }^{\circ}$ plastic tube) were submerged in $1 \mathrm{~mL}$ of GM. Tubes were shaken with a vortex to release the pollen grains from the anthers. Flowers were removed with a pair of tweezers and pollen suspension was then 
centrifuged at $4000 \mathrm{~g}$ for $7 \mathrm{~min}$. New GM was added to the pellet and pollen were transferred in 96-well-plates (ThermoFisher ${ }^{\circ}$ ) or in $\mu$-slides 18 -well (Ibidi $^{\circ}$ ) to be observed under an inverted microscopeor a confocal inverted microscope respectively and grown at $22{ }^{\circ} \mathrm{C}$ in the dark.

Pollen grains were collected from freshly dehisced anthers, and the stamens of three flowers (tobacco) or five flowers (tomato) were submerged in $5 \mathrm{~mL}$ of BK medium [1.62 $\mathrm{mM} \mathrm{H}_{3} \mathrm{BO}_{3}, 1.25 \mathrm{mM} \mathrm{Ca}\left(\mathrm{NO}_{3}\right)_{2}, 4 \mathrm{H}_{2} \mathrm{O}$, $2.97 \mathrm{mM} \mathrm{KNO}_{3}$ and $1.65 \mathrm{mM} \mathrm{MgSO}_{4}, 7 \mathrm{H}_{2} \mathrm{O}$ ] [103] containing $15 \%$ sucrose. Pollen grains were suspended in the GM by vortex, and the stamens were removed with tweezers. Tomato pollen tubes were grown in glass vials at $22^{\circ} \mathrm{C}$ in the dark for $6 \mathrm{~h}$ under agitation. Tobacco pollen tubes were grown in 24-well-plates (ThermoFisher $\left.{ }^{\circ}\right)$, without agitation at $22^{\circ} \mathrm{C}$ in the dark.

Pollen grains were considered as germinated when the length of the tube was longer than the diameter of the pollen grain. When burst, smaller pollen tubes were considered as "early burst" whereas longer pollen tubes were considered as "lately burst". When no apparent tube tip was observed, pollen grains were considered as nongerminated.

\section{Chemical screen}

A set of 258 compounds, representative of the chemical diversity (centroids approach) of the chemical library of the CERMN (Centre d'Etudes et de Recherche sur le Médicament de Normandie, Normandie Univ, UniCaen, France), was screened. Compounds were solubilized in $100 \%$ DMSO at $10 \mathrm{mM}$, aliquoted and stored at $-80^{\circ} \mathrm{C}$. For the primary screen, compounds were used at $20 \mu \mathrm{M}$ (diluted in GM) and selected for their abilities to induce pollen tube morphology. For the primary screen, the negative control was $0.1 \%$ DMSO. Molecule screening and the dose-response effects were performed in 96-well-plates.

Two compounds were then selected that we named Disruptol-A and Disruptol-B (Fig. 1a). Another compound (galvestine-1) was also used in the study (Fig. 1a). Galvestine-1 is known to reduce pollen tube length in vitro [54]. The negative control of galvestine-1 was G0. G0 possess a galvestine-1 structure modification that leads to the loss of bioactivity (Fig. 1a) [54].

The dose-effects of the compounds were tested on pollen grains, as described above with concentrations ranging from $0.5,1,5,10,20$ and $30 \mu \mathrm{M}$. Compounds at $10 \mathrm{mM}$ in DMSO were diluted in distilled water to reach a concentration of $500 \mu \mathrm{M}$. Different volumes of DMSO $5 \%$, the compound at $500 \mu \mathrm{M}$ and GM were mixed to get a final DMSO concentration of $0.3 \%$ for all the treatments.

\section{Cytochemical staining \\ Callose staining}

Decolorized aniline blue in $100 \mathrm{mM} \mathrm{K}_{2} \mathrm{HPO}_{4} 1 \% \mathrm{pH} 12$ was used to localize callose [102]. Decolorized aniline blue was directly added to the medium after $6 \mathrm{~h}$ of culture at a final concentration of $0.1 \%$. The observation was performed after $2 \mathrm{~h}$ of incubation in the dark at room temperature.

\section{Superoxide detection}

Superoxide anion $\left(\mathrm{O}_{2}{ }^{*-}\right)$ was detected using nitro blue tetrazolium (NBT; Alfa Aesar ${ }^{\circ}$ ). NBT solution was prepared in GM at $7 \mathrm{mM}$ and incubated for $20 \mathrm{~min}$ with pollen tubes at a final concentration of $1.2 \mathrm{mM}$ [92].

\section{Immunolocalization of Arabidopsis pollen tube cell wall epitopes}

Two primary monoclonal antibodies (LM19 and LM2, PlantProbes) were used. The mAb LM19 recognizes epitopes associated with low methylesterified homogalacturonan (HG) domain of pectin [104] whereas LM2 was generated against rice AGPs and recognizes a carbohydrate epitope containing a $\beta$-linked glucuronic acid [105].

After $6 \mathrm{~h}$ of culture, a fixation medium containing PIPES $100 \mathrm{mM}, 4 \mathrm{mM} \mathrm{MgSO}_{4} 7 \mathrm{H}_{2} \mathrm{O}, 4 \mathrm{mM}$ EGTA, $10 \%(w / v)$ sucrose and $5 \%(\mathrm{v} / \mathrm{v})$ of paraformaldehyde $\mathrm{pH} 7.5$ was added to the GM and incubated overnight at $4{ }^{\circ} \mathrm{C}$. Pollen tubes were centrifuged at $4000 \mathrm{~g}$ for $7 \mathrm{~min}$. The pellet was suspended in $200 \mu \mathrm{L}$ of Phosphate Buffer Saline (PBS: $137 \mathrm{mM} \mathrm{NaCl}, 2.7 \mathrm{mM} \mathrm{KCl}, 7 \mathrm{mM} \mathrm{Na} \mathrm{HPO}_{4} 2 \mathrm{H}_{2} \mathrm{O}$, $1.5 \mathrm{mM} \mathrm{KH} \mathrm{KH}_{4} \mathrm{PO}^{\mathrm{pH}}$ ) and then deposited on a $\mu$-Slide VI ${ }^{0.4}$ Poly-L-lysine (Ibidi ${ }^{\circ}$ ), incubated overnight at room temperature to fix the pollen tubes on the lysine matrix and then rinsed 3 times with PBS before being incubated with PBS 3\% fat-free milk for $30 \mathrm{~min}$ at room temperature. Pollen tubes were then rinsed 3 times with PBS. Primary antibodies were diluted at 1:5 with PBS and incubated overnight at $4{ }^{\circ} \mathrm{C}$ in the dark. Pollen tubes were rinsed 3 times with PBS and the secondary anti-rat antibody combined with fluorescein isothiocyanate (FITC; Sigma) diluted at 1:50 with PBS was incubated for $3 \mathrm{~h}$ at $30^{\circ} \mathrm{C}$. Negative controls were carried out by omitting the primary antibody. Before observation, pollen tubes were rinsed three times with PBS and suspended in a mix of citifluor/PBS (v/v). Observations were made as indicated below.

\section{Microscopy and image acquisition}

A confocal inverted microscope Leica SP2 was used to observe pollen tubes expressing $p L A T 52:$ :lifeact-mEGFP and $p C L$-CRIB4-GFP using a $\mu$-slide 18 -wells (Ibidi ${ }^{\circ}$ ). Images were acquired every $2 \mathrm{~s} 915 \mathrm{msec}$ for $5 \mathrm{~min}$. Different filter sets were used, pLAT52::lifeact-mEGFP (absorption 488 
$\mathrm{nm}$, emission 505-545 nm); $p$ CL-CRIB4-GFP (absorption $488 \mathrm{~nm}$, emission 498-560 nm).

An inverted microscope Leica DMI 6000B was used to observe phenotypes under bright field or epi-fluorescence for aniline blue and FITC with different filter sets (absorption, $405 \mathrm{~nm}$; emission, $523 \mathrm{~nm}$ or absorption, 460-500 nm; emission, respectively).

The program ImageJ [106] was used to determine manually on each picture the pollen tube germination rate, abnormal pollen tube shape, pollen tube length and diameter. For ROS quantification with NBT, pictures were transformed as grayscale images, a mark was drawn from the tip to $30 \mu \mathrm{m}$ behind and the surface was manually selected using freehand selection tool. The mean value of the pixel intensity was obtained with the measure tool.

\section{Statistical analyses}

Data were treated with $\mathrm{R}$ software [107] and represent the mean \pm SEM. Pairwise comparison were performed with the Dunnett's test or with Wilcoxon's test analysis with Holm adjustment according to parametric and non-parametric batch of dataset. Significant differences were ${ }^{" \prime} P<0.05,{ }^{* *} P<0.01$ and ${ }^{* * *} P<0.001$.

\section{Additional files}

Additional file 1: Figure S1. Dose-response effect of the compounds on (a) Solanum lycopersicum and (b) Nicotiana tabacum pollen tubes after $6 \mathrm{~h}$ of culture. (PDF $3876 \mathrm{~kb}$ )

Additional file 2: Figure S2. Time-lapse observations of actin dynamics in Arabidopsis thaliana pollen tubes treated for 2, 4 and $6 \mathrm{~h}$ with the compounds. (PDF $220 \mathrm{~kb}$ )

Additional file 3: Video S1. Time-lapse imaging of actin dynamics in untreated Arabidopsis thaliana pollen tubes after $6 \mathrm{~h}$ of growth. A frame was acquired every $3 \mathrm{~s}$ during $5 \mathrm{~min}$. (MP4 $538 \mathrm{~kb}$ )

Additional file 4: Video S2. Time-lapse imaging of actin dynamics in Arabidopsis thaliana pollen tubes treated for $6 \mathrm{~h}$ with Disruptol-A. A frame was acquired every $3 \mathrm{~s}$ during $5 \mathrm{~min}$. (MP4 $967 \mathrm{~kb}$ )

Additional file 5: Video S3. Time-lapse imaging of actin dynamics in Arabidopsis thaliana pollen tubes treated for $6 \mathrm{~h}$ with Disruptol-B. A frame was acquired every $3 \mathrm{~s}$ during $5 \mathrm{~min}$. (MP4 $668 \mathrm{~kb}$ )

Additional file 6: Figure S3. Time-lapse imaging of RIC4 dynamics in Arabidopsis thaliana pollen tubes treated for 2, 4 and $6 \mathrm{~h}$ with the compounds. (PDF $717 \mathrm{~kb}$ )

Additional file 7: Figure S4. Time-lapse imaging of RIC4 dynamics of a pollen tube treated with Disruptol-B for 2 h. (PDF 169 kb)

\section{Abbreviations}

AGPS: arabinogalactan proteins; CDC42: Cell division control protein 42; CRIB: Cdc42/Rac-interactive binding; DMSO: Diméthylsulfoxyde; HG: Homogalacturonan; IKK: Inhibitor of nuclear factor kappa-B kinase; LM: Leeds Monoclonal; MGDG: Monogalactosyldiacylglycerol; NADPH oxidase: $\beta$-nicotinamide adenine dinucleotide phosphate oxidase; NBT: Nitroblue tetrazolium; PBS: Phosphate buffer saline; PIP5K: Phosphatidylinositol-4-phosphate (PI4P) 5-kinases; RBOH: Respiratory burst oxidase homolog; RIC4: ROP-interactive CRIB motif-containing protein 4; ROP1: Rho-related GTPases in plants 1; ROS: Reactive oxygen species

\section{Acknowledgements}

The authors are grateful to the Cell Imaging Platform of Université de Rouen Normandie PRIMACEN (http://www.primacen.fr). We are also thankful to Pr. Shanjin Huang (Chinese Academy of Sciences, Beijing, China) and Zhenbiao Yang (University of California, Riverside, USA) for the kind gift of the transformed seeds.

\section{Funding}

This work was partly funded by the Université de Rouen Normandie and the French ministry of Research. FL and JD were funded by a PhD fellowship from the Université de Rouen Normandie and FD from the Région Normandie.

\section{Availability of data and materials}

All data analyzed in this study are included in this published article and its additional files.

\section{Authors' contributions}

FD performed the primary screen under the supervision of $A D$ and J-CM, FL carried out most of the experiment with the help of JD, FL analyzed the data with the input of JD, DF, PD, AL and J-CM and drafted the manuscript; CR and PD provided the chemical library and the two purified compounds further investigated, DF provided Galvestine and GO, AL and J-CM designed and directed the study. All authors have participated in the writing and approved the final manuscript.

\section{Ethics approval and consent to participate}

Not applicable

\section{Consent for publication}

Not applicable

\section{Competing interests}

The authors declare that they have no competing interests.

\section{Publisher's Note}

Springer Nature remains neutral with regard to jurisdictional claims in published maps and institutional affiliations.

\section{Author details}

${ }^{1}$ Normandie Université, UNIROUEN, Laboratoire Glycobiologie et Matrice Extracellulaire Végétale EA4358, Fédération de Recherche "NORVEGE"- FED 4277, 76000 Rouen, France. 'Laboratoire de Physiologie Cellulaire et Végétale, CNRS, CEA, INRA, Université Grenoble Alpes, Institut de Biosciences et Biotechnologies de Grenoble, CEA Grenoble, 38000 Grenoble, cedex 9, France. ${ }^{3}$ Normandie Université, UNICAEN, Centre d'Etudes et de Recherche sur le Médicament de Normandie, CNRS 3038 INC3M, SFR ICORE, 14032, Caen, France. ${ }^{4}$ Present Address: LPS-BioSciences, Bâtiment 409, Université Paris-Sud, 91400 Orsay, France.

Received: 5 November 2018 Accepted: 27 March 2019

Published online: 22 April 2019

\section{References}

1. Palanivelu R, Preuss D. Pollen tube targeting and axon guidance: parallels in tip growth mechanisms. Trends Cell Biol. 2000;10:517-24

2. Mollet J-C, Faugeron C, Morvan H. Cell adhesion, separation and guidance in compatible plant reproduction. In: Annual plant reviews volume 25: plant cell separation and adhesion. Oxford: Wiley-Blackwell; 2007. p. 69-90.

3. Okuda S, Tsutsui H, Shiina K, Sprunck S, Takeuchi H, Yui R, et al. Defensin-like polypeptide LUREs are pollen tube attractants secreted from synergid cells. Nature. 2009;458:357-61.

4. Chae K, Lord EM. Pollen tube growth and guidance: roles of small, secreted proteins. Ann Bot. 2011;108:627-36

5. Higashiyama T, Takeuchi $\mathrm{H}$. The mechanism and key molecules involved in pollen tube guidance. Annu Rev Plant Biol. 2015;66:393-413.

6. Cheung AY, Wu H. Structural and signaling networks for the polar cell growth machinery in pollen tubes. Annu Rev Plant Biol. 2008:59:547-72.

7. Feijó JA, Sainhas J, Holdaway-Clarke T, Cordeiro MS, Kunkel JG, Hepler PK. Cellular oscillations and the regulation of growth: the pollen tube paradigm. BioEssays. 2000;23:86-94. 
8. Hepler PK, Vidali L, Cheung AY. Polarized cell growth in higher plants. Annu Rev Cell Dev Biol. 2001;17:159-87.

9. Holdaway-Clarke TL, Feijó JA, Hackett GR, Kunkel JG, Hepler PK. Pollen tube growth and the intracellular cytosolic calcium gradient oscillate in phase while extracellular calcium influx is delayed. Plant Cell. 1997;9:1999-2010.

10. Messerli MA, Créton $R$, Jaffe LF, Robinson KR. Periodic increases in elongation rate precede increases in cytosolic Ca2+ during pollen tube growth. Dev Biol. 2000;222:84-98.

11. Steinhorst L, Kudla J. Calcium - a central regulator of pollen germination and tube growth. Biochim Biophys Acta BBA - Mol Cell Res. 2013;1833:1573-81.

12. Potocký M, Jones MA, Bezvoda R, Smirnoff N, Žárský V. Reactive oxygen species produced by NADPH oxidase are involved in pollen tube growth. New Phytol. 2007;174:742-51

13. Speranza A, Crinelli R, Scoccianti V, Geitmann A. Reactive oxygen species are involved in pollen tube initiation in kiwifruit: ROS and pollen germination. Plant Biol. 2012:14:64-76.

14. Lassig R, Gutermuth T, Bey TD, Konrad KR, Romeis T. Pollen tube NAD(P)H oxidases act as a speed control to dampen growth rate oscillations during polarized cell growth. Plant J. 2014;78:94-106.

15. Boisson-Dernier A, Lituiev DS, Nestorova A, Franck CM, Thirugnanarajah S, Grossniklaus U. ANXUR receptor-like kinases coordinate cell wall integrity with growth at the pollen tube tip via NADPH oxidases. PLoS Biol. 2013;11:e1001719.

16. Fu Y, Wu G, Yang Z. Rop GTPase-dependent dynamics of tip-localized Factin controls tip growth in pollen tubes. J Cell Biol. 2001;152:1019-32.

17. Qu X, Zhang H, Xie Y, Wang J, Chen N, Huang S. Arabidopsis Villins promote actin turnover at pollen tube tips and facilitate the construction of actin collars. Plant Cell. 2013;25:1803-17.

18. Gibbon BC, Kovar DR, Staiger CJ. Latrunculin B has different effects on pollen germination and tube growth. Plant Cell. 1999;11:2349-63.

19. Vidali L, McKenna ST, Hepler PK. Actin polymerization is essential for pollen tube growth. Mol Biol Cell. 2001;12:2534-45.

20. Lovy-Wheeler A, Wilsen KL, Baskin TI, Hepler PK. Enhanced fixation reveals the apical cortical fringe of actin filaments as a consistent feature of the pollen tube. Planta. 2005;221:95-104.

21. Staiger CJ, Poulter NS, Henty JL, Franklin-Tong VE, Blanchoin L. Regulation of actin dynamics by actin-binding proteins in pollen. J Exp Bot. 2010;61:1969-86

22. Rounds CM, Hepler PK, Winship LJ. The apical actin fringe contributes to localized cell wall deposition and polarized growth in the Lily pollen tube. Plant Physiol. 2014;166:139-51.

23. Kost B, Lemichez E, Spielhofer P, Hong Y, Tolias K, Carpenter C, et al. Rac homologues and compartmentalized phosphatidylinositol 4, 5-bisphosphate act in a common pathway to regulate polar pollen tube growth. J Cell Biol. 1999;145:317-30.

24. Molendijk AJ. Arabidopsis thaliana Rop GTPases are localized to tips of root hairs and control polar growth. EMBO J. 2001;20:2779-88.

25. Fu Y. The ROP2 GTPase controls the formation of cortical fine F-Actin and the early phase of directional cell expansion during Arabidopsis organogenesis. Plant Cell. 2002;14:777-94.

26. Jones MA, Shen J-J, Fu Y, Li H, Yang Z, Grierson CS. The Arabidopsis Rop2 GTPase is a positive regulator of both root hair initiation and tip growth. Plant Cell. 2002;14:763-76.

27. Burkart GM, Baskin TI, Bezanilla M. A family of ROP proteins that suppresses actin dynamics, and is essential for polarized growth and cell adhesion. Cell Sci. 2015;128:2553-64.

28. Gu Y, Fu Y, Dowd P, Li S, Vernoud V, Gilroy S, et al. A Rho family GTPase controls actin dynamics and tip growth via two counteracting downstream pathways in pollen tubes. J Cell Biol. 2005;169:127-38.

29. Gu Y, Vernoud V, Fu Y, Yang Z. ROP GTPase regulation of pollen tube growth through the dynamics of tip-localized F-actin. J Exp Bot. 2003;54:93-101.

30. Lord EM, Russell SD. The mechanisms of pollination and fertilization in plants. Annu Rev Cell Dev Biol. 2002;18:81-105.

31. Dardelle F, Lehner A, Ramdani Y, Bardor M, Lerouge P, Driouich A, et al. Biochemical and immunocytological characterizations of Arabidopsis pollen tube cell wall. Plant Physiol. 2010;153:1563-76.

32. Chebli Y, Kaneda M, Zerzour R, Geitmann A. The cell wall of the Arabidopsis pollen tube: spatial distribution, recycling, and network formation of polysaccharides. Plant Physiol. 2012;160:1940-55.

33. Lord E. Adhesion and cell movement during pollination: cherchez la femme. Trends Plant Sci. 2000;5:368-73.
34. Cai G, Faleri C, Del Casino C, Emons AMC, Cresti M. Distribution of callose synthase, cellulose synthase, and sucrose synthase in tobacco pollen tube is controlled in dissimilar ways by actin filaments and microtubules. Plant Physiol. 2011;155:1169-90.

35. Mogami N, Miyamoto M, Onozuka M, Nakamura N. Comparison of callose plug structure between dicotyledon and monocotyledon pollen germinated in vitro. Grana. 2006;45:249-56.

36. Qin P, Ting D, Shieh A, McCormick S. Callose plug deposition patterns vary in pollen tubes of Arabidopsis thaliana ecotypes and tomato species. BMC Plant Biol. 2012;12:178.

37. Parre E, Geitmann A. Pectin and the role of the physical properties of the cell wall in pollen tube growth of Solanum chacoense. Planta. 2005b;220:582-92.

38. Geitmann A, Steer M. The architecture and properties of the pollen tube cell wall. In: Malhó R, editor. The pollen tube. Berlin/Heidelberg: SpringerVerlag; 2006. p. 177-200.

39. Qin Y, Yang Z. Rapid tip growth: insights from pollen tubes. Semin Cell Dev Biol. 2011;22:816-24

40. Mollet J-C, Leroux C, Dardelle F, Lehner A. Cell wall composition, biosynthesis and remodeling during pollen tube growth. Plants. 2013;2:107-47.

41. Malho R. Tube growth and reorientation. Plant Cell. 1995;7:1173-84.

42. Parre E, Geitmann. More than a leak sealant. The mechanical properties of callose in pollen tubes. Plant Physiol. 2005a;137:274-86.

43. Klahre $U$, Kost B. Tobacco RhoGTPase ACTIVATING PROTEIN1 spatially restricts signaling of RAC/Rop to the apex of pollen tubes. Plant Cell. 2006;18:3033-46.

44. Aouar L, Chebli Y, Geitmann A. Morphogenesis of complex plant cell shapes: the mechanical role of crystalline cellulose in growing pollen tubes. Sex Plant Reprod. 2010;23:15-27.

45. Choe S, Dilkes BP, Fujioka S, Takatsuto S, Sakurai A, Feldmann KA. The DWF4 gene of Arabidopsis encodes a cytochrome P450 that mediates multiple 22alpha-hydroxylation steps in brassinosteroid biosynthesis. Plant Cell. 1998;10:231-43

46. Asami T, Min YK, Nagata N, Yamagishi K, Takatsuto S, Fujioka S, et al. Characterization of brassinazole, a triazole-type brassinosteroid biosynthesis inhibitor. Plant Physiol. 2000;123:93-100.

47. Armstrong JI, Yuan S, Dale JM, Tanner VN, Theologis A. Identification of inhibitors of auxin transcriptional activation by means of chemical genetics in Arabidopsis. Proc Natl Acad Sci U S A. 2004;101:14978-83.

48. Kombrink E, Kaiser M. Editorial: when chemistry meets biology - generating innovative concepts, methods and tools for scientific discovery in the plant sciences. Front Plant Sci. 2016;7:76.

49. Knoth C, Salus MS, Girke T, Eulgem T. The synthetic elicitor 3,5-dichloroanthranilic acid induces NPR1-dependent and NPR1-independent mechanisms of disease resistance in Arabidopsis. Plant Physiol. 2009;150:333-47.

50. Noutoshi Y, Okazaki M, Kida T, Nishina Y, Morishita Y, Ogawa T, et al. Novel plant immune-priming compounds identified via high-throughput chemical screening target salicylic acid glucosyltransferases in Arabidopsis. Plant Cell. 2012:24:3795-804

51. Robert S, Chary SN, Drakakaki G, Li S, Yang Z, Raikhel NV, et al. Endosidin1 defines a compartment involved in endocytosis of the brassinosteroid receptor BRI1 and the auxin transporters PIN2 and AUX1. Proc Natl Acad Sci. 2008;105:8464-9.

52. Chuprov-Netochin $R$, Neskorodov $Y$, Marusich $E$, Mishutkina $Y$, Volynchuk $P$, Leonov $S$, et al. Novel small molecule modulators of plant growth and development identified by high-content screening with plant pollen. BMC Plant Biol. 2016;16:192

53. Ung N, Brown MQ, Hicks GR, Raikhel NV. An approach to quantify endomembrane dynamics in pollen utilizing bioactive chemicals. Mol Plant. 2013;6:1202-13.

54. Botté CY, Deligny M, Roccia A, Bonneau A-L, Saïdani N, Hardré H, et al. Chemical inhibitors of monogalactosyldiacylglycerol synthases in Arabidopsis thaliana. Nat Chem Biol. 2011;7:834-42.

55. Zhang H, Qu X, Bao C, Khurana P, Wang Q, Xie Y, et al. Arabidopsis VILLIN5, an actin filament bundling and severing protein, is necessary for normal pollen tube growth. Plant Cell. 2010;22:2749-67.

56. Qu H-Y, Shang Z-L, Zhang S-L, Liu L-M, Wu J-Y. Identification of hyperpolarization-activated calcium channels in apical pollen tubes of Pyrus pyrifolia. New Phytol. 2007;174:524-36.

57. Tiwari SC, Polito VS. Spatial and temporal organization of actin during hydration, activation, and germination of pollen inPyrus communis L.: a population study. Protoplasma. 1988;147:5-15. 
58. Thomas SG, Huang S, Li S, Staiger CJ, Franklin-Tong VE. Actin depolymerization is sufficient to induce programmed cell death in selfincompatible pollen. J Cell Biol. 2006;174:221-9.

59. Wilsen KL, Lovy-Wheeler A, Voigt B, Menzel D, Kunkel JG, Hepler PK. Imaging the actin cytoskeleton in growing pollen tubes. Sex Plant Reprod. 2006;19:51-62.

60. Chaidee A, Foissner I, Pfeiffer W. Cell-specific association of heat shockinduced proton flux with actin ring formation in Chenopodium cells: comparison of auto- and heterotroph cultures. Protoplasma. 2008;234:33.

61. Papuga J, Hoffmann C, Dieterle M, Moes D, Moreau F, Tholl S, et al. Arabidopsis LIM proteins: a family of actin bundlers with distinct expression patterns and modes of regulation. Plant Cell. 2010;22:3034-52.

62. Smertenko AP, Deeks MJ, Hussey PJ. Strategies of actin reorganisation in plant cells. J Cell Sci. 2010;123(Pt 17):3019-28.

63. van der Honing HS, van Bezouwen LS, Emons AMC, Ketelaar T. High expression of Lifeact in Arabidopsis thaliana reduces dynamic reorganization of actin filaments but does not affect plant development Cytoskeleton. 2011;68:578-87.

64. Vogler F, Sprunck S. F-actin forms mobile and unwinding ring-shaped structures in germinating Arabidopsis pollen expressing Lifeact. Plant Signal Behav. 2015:10:e1075684.

65. Kobayashi K, Awai K, Takamiya K, Ohta H. Arabidopsis type B Monogalactosyldiacylglycerol synthase genes are expressed during pollen tube growth and induced by phosphate starvation. Plant Physiol. 2004;134:640-8.

66. Poulter NS, Staiger CJ, Rappoport JZ, Franklin-Tong VE. Actin-binding proteins implicated in the formation of the punctate actin foci stimulated by the self-incompatibility response in Papaver. Plant Physiol. 2010;152:1274-83

67. Poulter NS, Bosch M, Franklin-Tong VE. Proteins implicated in mediating self-incompatibility-induced alterations to the actin cytoskeleton of Papaver pollen. Ann Bot. 2011;108:659-75.

68. Li H. Control of pollen tube tip growth by a Rop GTPase dependent pathway that leads to tip-localized calcium influx. Plant Cell. 1999;11:1731-42

69. Cheung AY, Niroomand S, Zou Y, Wu H-M. A transmembrane formin nucleates subapical actin assembly and controls tip-focused growth in pollen tubes. Proc Natl Acad Sci. 2010;107:16390-5.

70. Snow AA, Spira TP. Differential pollen-tube growth rates and nonrandom fertilization in Hibiscus moscheutos (Malvaceae). Am J Bot USA. 1991;78:1419-26.

71. Chen T, Teng N, Wu X, Wang Y, Tang W, Šamaj J, et al. Disruption of actin filaments by latrunculin B affects cell wall construction in Picea meyeri pollen tube by disturbing vesicle trafficking. Plant Cell Physiol. 2007;48:19-30.

72. Delmer DP. Cellulose biosynthesis. Annu Rev Plant Physiol. 1987;38:259-90.

73. Somerville C. Cellulose synthesis in higher plants. Annu Rev Cell Dev Biol. 2006;22:53-78

74. Mollet J-C, Kim S, Jauh G-Y, Lord EM. Arabinogalactan proteins, pollen tube growth, and the reversible effects of Yariv phenylglycoside. Protoplasma. 2002;219:89-98.

75. Nguema-Ona E, Coimbra S, Vicre-Gibouin M, Mollet J-C, Driouich A. Arabinogalactan proteins in root and pollen-tube cells: distribution and functional aspects. Ann Bot. 2012:110:383-404.

76. Geitmann A. The rheological properties of the pollen tube cell wall. In: Cresti M, Cai G, Moscatelli A, editors. Fertilization in higher plants. Berlin, Heidelberg: Springer Berlin Heidelberg; 1999. p. 283-302.

77. Taylor LP, Hepler PK. Pollen germination and tube growth. Annu Rev Plant Biol. 1997:48:461-91.

78. O'Neill MA, Ishii T, Albersheim P, Darvill AG. Rhamnogalacturonan II: structure and function of a borate cross-linked cell wall pectic polysaccharide. Annu Rev Plant Biol. 2004;55:109-39.

79. Stepka M, Ciampolini F, Charzyńska M, Cresti M. Localization of pectins in the pollen tube wall of Ornithogalum virens $L$. does the pattern of pectin distribution depend on the growth rate of the pollen tube? Planta. 2000;210:630-5.

80. Vidali L, Burkart GM, Augustine RC, Kerdavid E, Tüzel E, Bezanilla M. Myosin XI is essential for tip growth in Physcomitrella patens. Plant Cell. 2010;22: 1868-82.

81. Rojas ER, Hotton S, Dumais J. Chemically mediated mechanical expansion of the pollen tube cell wall. Biophys J. 2011;101:1844-53.

82. Bibeau JP, Kingsley JL, Furt F, Tuzel E, Vidali L. F-Actin meditated focusing of vesicles at the cell tip is essential for polarized growth. Plant Physiol. 2017. https://doi.org/10.1104/pp.17.00753.
83. Roy S, Jauh GY, Hepler PK, Lord EM. Effects of Yariv phenylglycoside on cell wall assembly in the lily pollen tube. Planta. 1998;204:450-8.

84. Foyer $\mathrm{CH}$, Noctor G. Oxidant and antioxidant signalling in plants: a reevaluation of the concept of oxidative stress in a physiological context Plant Cell Environ. 2005;28:1056-71.

85. Mittler R, Vanderauwera S, Suzuki N, Miller G, Tognetti VB, Vandepoele K, et al. ROS signaling: the new wave? Trends Plant Sci. 2011;16:300-9.

86. Wrzaczek M, Brosché M, Kangasjärvi J. ROS signaling loops - production, perception, regulation. Curr Opin Plant Biol. 2013;16:575-82.

87. Baxter A, Mittler R, Suzuki N. ROS as key players in plant stress signalling. J Exp Bot. 2014;65:1229-40.

88. Fry SC. Oxidative scission of plant cell wall polysaccharides by ascorbateinduced hydroxyl radicals. Biochem J. 1998;332:507.

89. Prado AM. Nitric oxide is involved in growth regulation and re-orientation of pollen tubes. Development. 2004:131:2707-14.

90. Wilkins KA, Bancroft J, Bosch M, Ings J, Smirnoff N, Franklin-Tong VE. Reactive oxygen species and nitric oxide mediate actin reorganization and programmed cell death in the self-incompatibility response of Papaver. Plant Physiol. 2011;156:404-16.

91. Müller K, Linkies A, Vreeburg RAM, Fry SC, Krieger-Liszkay A, LeubnerMetzger G. In vivo cell wall loosening by hydroxyl radicals during cress seed germination and elongation growth. Plant Physiol. 2009;150:1855-65.

92. Aloisi I, Cai G, Tumiatti V, Minarini A, Del Duca S. Natural polyamines and synthetic analogs modify the growth and the morphology of Pyrus communis pollen tubes affecting ROS levels and causing cell death. Plant Sci. 2015:239:92-105.

93. Sugiyama H, Yoshida M, Mori K, Kawamoto T, Sogabe S, Takagi T, et al. Synthesis and structure activity relationship studies of benzothieno $[3,2-b]$ furan derivatives as a novel class of IKK $\beta$ inhibitors. Chem Pharm Bull. 2007;55:613-24.

94. Wright BD, Simpson C, Stashko M, Kireev D, Hull-Ryde EA, Zylka MJ, et al. Development of a high-throughput screening assay to identify inhibitors of the lipid kinase PIP5K1C.J Biomol Screen. 2015;20:655-62.

95. Foti M, Audhya A, Emr SD. Sac1 lipid phosphatase and Stt4 phosphatidylinositol 4-kinase regulate a pool ofphosphatidylinositol 4phosphate that functions in the control of the actin cytoskeleton and vacuole morphology. Mol Biol Cell. 2001;12:2396-411.

96. Zhang W-T, Li E, Guo Y-K, Yu S-X, Wan Z-Y, Ma T, et al. Arabidopsis VAC14 is critical for pollen development through mediating vacuolar organization. Plant Physiol. 2018;177:1529.

97. Ischebeck T, Stenzel I, Hempel F, Jin X, Mosblech A, Heilmann I. Phosphatidylinositol-4,5-bisphosphate influences Nt-Rac5-mediated cell expansion in pollen tubes of Nicotiana tabacum. Plant J Cell Mol Biol. 2011;65:453-68

98. Guan Y, Guo J, Li H, Yang Z. Signaling in pollen tube growth: crosstalk, feedback, and missing links. Mol Plant. 2013:6:1053-64.

99. Vidali L, Rounds CM, Hepler PK, Bezanilla M. Lifeact-mEGFP reveals a dynamic apical F-Actin network in tip growing plant cells. PLoS One. 2009:4:e5744.

100. Rong D, Luo N, Mollet JC, Liu X, Yang Z. Salicylic acid regulates pollen tip growth through an NPR3/NPR4-independent pathway. Mol Plant. 2016;9:1478-91

101. Boavida LC, McCormick S. TECHNICAL ADVANCE: Temperature as a determinant factor for increased and reproducible in vitro pollen germination in Arabidopsis thaliana: temperature effect on Arabidopsis pollen germination. Plant J. 2007;52:570-82.

102. Johnson-Brousseau SA, McCormick S. A compendium of methods useful for characterizing Arabidopsis pollen mutants and gametophytically- expressed genes. Plant J. 2004;39:761-75.

103. Brewbaker JL, Kwack BH. The essential role of calcium ion in pollen germination and pollen tube growth. Am J Bot. 1963;50:859.

104. Verhertbruggen Y, Marcus SE, Haeger A, Ordaz-Ortiz JJ, Knox JP. An extended set of monoclonal antibodies to pectic homogalacturonan. Carbohydr Res. 2009;344:1858-62.

105. Yates EA, Valdor JF, Haslam SM, Morris HR, Dell A, Mackie W, et al. Characterization of carbohydrate structural features recognized by antiarabinogalactan-protein monoclonal antibodies. Glycobiology. 1996;6:131-9.

106. Abràmoff MD, Magalhães PJ, Ram SJ. Image processing with ImageJ. Biophoton Int. 2004;11:36-42

107. R Development Core Team. R: A language and environment for statistical computing. R Foundation for Statistical Computing, Vienna, Austria. ISBN 3900051-07-0. URL http://www.R-project.org. 2008. 